\title{
The Willingness to Pay for Diversification
}

\author{
Ola Mahmoud*
}

April 21, 2021

\begin{abstract}
Diversification is a fundamental concept in economics and finance. This paper argues that decision makers have an intrinsic preference for diversification that is responsive to cost, and that this willingness to pay for diversification is driven by risk aversion and loss aversion. In an experiment replicating a portfolio choice problem, the value of diversification is estimated to be at $5 \%$ of the initial endowment of approximately USD 100. Moreover, risk averse and loss averse individuals are willing to pay more for diversification. These findings point to the idea that diversification is a fundamental preference and may help explain portfolio choice anomalies such as irrational diversification, the diversification bias, and overdiversification.
\end{abstract}

Keywords: diversification, portfolio choice, diversification cost, irrational diversification, diversification bias, risk aversion, loss aversion

JEL Classification: C91, D01, D90, G11, G40

\section{Introduction}

Diversification is a fundamental concept in economics, finance and decision theory. From a broad perspective, it conveys the idea of introducing variety to a set of objects by not putting all of one's proverbial eggs into one basket. This is a paradigm that goes as far back as the Talmud (ca. 200 $\mathrm{CE}$ ), which states that "it is advisable for one that he should divide his money in three parts, one of which he shall invest in real estate, one of which in business, and the third part to remain always in his hands." In an economic context, Bernoulli (1738) may have been the first to formally argue for the benefits of diversification. In his fundamental 1738 article on the St. Petersburg paradox, Bernoulli (1738) argues by example that risk averse investors will want to diversify: "Another rule which may prove useful can be derived from our theory. This is the rule that it is advisable to divide goods which are exposed to some danger into several portions rather than to risk them all together." But perhaps the most prominent conceptual theory of diversification is that of Darwin (1859), who introduced the idea that a greater diversity of life forms is conducive to higher evolutionary fitness.

*University of Basel, Switzerland, and University of California at Berkeley, USA, email: ola . mahmoud@unibas . ch 
Today, there is general consensus that some form of diversification is beneficial in an array of seemingly disparate contexts: variety-seeking is typical of consumer behavior, diversity improves growth, innovation, and competition, and diversified choices provide a buffer against future uncertainty. In particular, desirability for diversification is a cornerstone of a broad range of decision making and portfolio choice models in economics and finance, lead by the seminal works of von Neumann and Morgenstern (1944) and Markowitz (1952).

However, the views of what constitutes diversification in decision making in general and in financial economics in particular differ substantially, and the way in which diversification is modelled, interpreted and implemented in the real world varies greatly. Indeed, there is a recent trend of evaluating certain diversifying decisions as being "anomalous" and "irrational" behavior. It is documented that even Harry Markowitz used a "naive" diversification heuristic when he made his own retirement investments. ${ }^{1}$ Moreover, there is evidence for heuristic behavior in contexts where diversification may not be optimal (Baltussen and Post, 2011). There is also evidence of a so-called "overdiversification bias" in practice, where costs and fees associated with splitting one's endowment are too high, leading to a suboptimal diversified portfolio.

The premise of this paper is that decision makers value the notion of diversification for the sake of diversification, regardless of the optimality of the diversified choice. This willingness to pay for diversification reflects a preference to diversify without instrumental motivation, and is therefore responsive to costs. In order to elicit this preference for diversification, the paper reports on an experiment in which diversification preference is measured through a sequence of simple gambles replicating a portfolio choice problem. If agents pay to invest in two options even though it would be possible to generate the same distribution of rewards without diversification, one can conclude that they have diversification preferences. The cost of diversifying is varied in each question, starting from zero cost and going up incrementally to the equivalent of about $10 \%$ of the initial holding. The value of diversification is estimated to be at $5 \%$ of the initial endowment of 100 Swiss Francs. The experiment further shows that risk averse and loss averse individuals are willing to pay more for diversification.

There is a multitude of empirical and experimental work documenting diversification without instrumental motives, at least according to standard economic theory. The literature has largely attributed this to a mistake or judgement bias. Rather than being an irrationality or bias, this paper takes a different view and argues that diversification preferences are intrinsic, the same way that, say, risk aversion has been argued to be intrinsic. Moreover, such diversification preferences are measurable in a simple experimental setting. This willingness to pay for diversification may explain some well-known behavioral investment and portfolio choice anomalies documented empirically and frequently observed in practice, such as the naive diversification bias, irrational diversification and the overdiversification bias. These anomalies in decision making may thus be due to an intrinsic want for diversity and its associated perceived benefits, rather than due to cognitive limits, financial illiteracy, or simply a mistake in judgement.

\footnotetext{
${ }^{1}$ Markowitz justifies his choice on psychological grounds: "My intention was to minimize my future regret. So I split my contributions fifty-fifty between bonds and equities" (Gigerenzer, 2010).
} 
The remainder of this paper is organized as follows. Section 2 gives an overview of the economic, decision theoretic and behavioral foundations of diversification and reviews previous literature documenting anomalous diversification behavior. Section 3 presents the main hypotheses and outlines the experiment's design, subjects, reward structure, and procedure. In Section 4, the results of the experiment are presented and discussed. Section 5 concludes.

\section{Rudiments of diversification}

The views of what constitutes diversification in economics and finance differ substantially. Even though desirability for diversification is a cornerstone of a broad range of economic models, the precise formal definition often takes a model-dependent form. Analogously, the way in which the notion of diversification is interpreted and implemented in the real world varies greatly. Traditional diversification paradigms are consistently violated in practice, and empirical evidence suggests that economic agents often choose diversification schemes other than those implied by Markowitz's portfolio theory (Markowitz, 1952) or von Neumann and Morgenstern's Expected Utility Theory (von Neumann and Morgenstern, 1944).

That said, there are generally two broad strands to the foundations of diversification, both of which are essentially traditional normative frameworks in which diversification preferences are derived from first principles. In financial economics, there is a tendency to reduce the notion of diversification to Markowitz's mean-variance paradigm. Markowitz's portfolio theory postulates that an investor should maximize portfolio return while minimizing portfolio risk, given by the return variance. Hence, diversification in finance is equivalent to the reduction of overall risk (but not generally its elimination). In microeconomic theory, on the other hand, diversification is generally associated with convexity of preferences and concavity of the utility function.

\subsection{Theoretic foundations}

I adopt the classical setup for risk assessment used in mathematical finance and portfolio choice. Consider a decision maker who chooses from the vector space $\mathscr{X}=\mathbb{L}^{\infty}(\Omega, \mathscr{F}, \mathbb{P})$ of essentially bounded real-valued random variables on a probability space $(\Omega, \mathscr{F}, \mathbb{P})$, where $\Omega$ is the set of states of nature, $\mathscr{F}$ is a $\sigma$-algebra of events, and $\mathbb{P}$ is a $\sigma$-additive probability measure on $(\Omega, \mathscr{F})$. Note that the decision maker is also able to form compound choices represented by the state-wise convex combination $\alpha x+(1-\alpha) y$ for $x, y \in \mathscr{X}$ and $\alpha \in[0,1]$, defined by $\alpha x(\omega)+(1-\alpha) y(\omega)$ for $\mathbb{P}$-almost all $\omega \in \Omega$. The space $\mathscr{X}$ is endowed with the order $x \geq y \Leftrightarrow x(\omega) \geq y(\omega)$ for $\mathbb{P}$ almost all $\omega \in \Omega$. The assumption that the outcome space is the set $\mathbb{R}$ of real numbers, which comes with an intrinsic ordering and mixing operations, enables a natural monetary interpretation of outcomes. The decision maker's preferences are represented by the complete and transitive binary relation $\succsim$ on $\mathscr{X}$. Moreover, emulating the majority of frameworks of economic theory, it seems reasonable to assume that decision makers prefer more to less. In particular, in view of the monetary interpretation of the space $\mathscr{X}$, a natural assumption on the preference relation $\succsim$ is 
monotonicity, that is for all $x, y \in \mathscr{X}, x \geq y \Longrightarrow x \succsim y$. Monotonicity of preferences is equivalent to having an increasing utility function $u$, which simply implies that an agent believes that "more is better"; a larger outcome yields greater utility, and for risky bets the agent would prefer a bet which is first-order stochastically dominant over an alternative bet. Continuity of preferences is also assumed for technical reasons, as it can be used as a sufficient condition for showing that preferences on infinite sets can have utility representations.

For $x \in \mathscr{X}, F_{x}$ denotes the cumulative distribution function of $x$, defined by $F_{x}(c)=\mathbb{P}[x \leq c]$ for $c \in \mathbb{R}$, and $e(x)$ is the expectation of $x$, that is, $e(x)=\int c d F_{x}(c)$. For $c \in \mathbb{R}, \delta_{c}$ denotes the degenerated random variable with $\delta_{c}(\omega)=c$ for $\mathbb{P}$-almost all $\omega \in \Omega$. The certainty equivalent of $x \in \mathscr{X}$ is the value $c(x) \in \mathbb{R}$ such that $x \sim \delta_{c(x)}$, i.e., $c(x)$ is the certain value which the decision maker views as equally desirable as a choice $x$ with uncertain outcome. The risk premium $\pi(x)$ of $x \in \mathscr{X}$ is the amount by which the expected return of a choice $x \in \mathscr{X}$ must exceed the value of the guaranteed outcome in order to make the uncertain and certain choices equally attractive. Formally, it is defined as $\pi(x)=e(x)-c(x)$.

An economic agent who chooses to diversify is understood to prefer variety over similarity. Axiomatically, preference for diversification is formalized as follows; see Dekel (1989).

Definition 1 (Preference for diversification). A preference relation $\succsim$ exhibits preference for diversification if for any $x_{1}, \ldots, x_{n} \in \mathscr{X}$ and $\alpha_{1}, \ldots, \alpha_{n} \in[0,1]$ for which $\sum_{i=1}^{n} \alpha_{i}=1$,

$$
x_{1} \sim \cdots \sim x_{n} \Longrightarrow \sum_{i=1}^{n} \alpha_{i} x_{i} \succsim x_{j} \quad \text { for all } j=1, \ldots, n .
$$

This definition states that an individual will want to diversify among a collection of choices all of which are ranked equivalently. The most common example of such diversification is within the universe of asset markets, where an investor faces a choice amongst risky assets. Three important aspects of Definition 1 are noteworthy at this stage, as they play a role in the design of the experiment (Section 3) and analysis of its results (Section 4). First, a crucial assumption underlying preferences for diversification is that of indifference between a set of alternatives. In practical terms, the design of the experiment accounts for this assumption by offering the decision maker equivalent assets that are uncorrelated. Second, if the preference relation in Definition 1 is strict, then the individual would naturally be willing to pay a cost for diversifying. The possibility of willingness to pay a cost is thus part of the definition since the preference relation is not indifference, but rather a weak preference for diversification. Third, Definition 1 does not give an indication as to which allocation vector $\left(\alpha_{1}, \ldots, \alpha_{n}\right)$ a decision maker should choose. When analyzing the experiment's results, the focus will therefore be on whether subjects diversify and not on their precise division in their allocation to the different options. ${ }^{2}$

\footnotetext{
${ }^{2}$ Various other definitions of diversification exist in the literature. Chateauneuf and Tallon (2002) introduce the weaker notion of sure diversification. Roughly, sure diversification stipulates that if the decision maker is indifferent between a collection of choices and can attain certainty by a convex combination of these choices, he/she should prefer that certain combination to any of the uncertain choices used in the combination. Also, Chateauneuf and Lakhnati (2007) introduce the concept of preference for strong diversification, which means that the decision maker will want to diversify between two choices that are identically distributed. Yet another notion of diversification was introduced by
} 
One hypothesis in this paper is that risk averse individuals have stronger preferences for diversification. The most common notion of risk aversion is based on the comparison between a random variable and its expected value. A decision maker is weakly risk averse if he/she always prefers the expected value of a random variable with certainty to the random variable itself. Formally, the preference relation $\succsim$ on $\mathscr{X}$ is weakly risk averse if $\delta_{e(x)} \succsim x$ for every $x \in \mathscr{X}$, where $e(x)$ denotes the expected value of the random variable $x$. A decision maker is weakly risk seeking if he/she always prefers any random variable to its expected value with certainty; formally if for all $x \in \mathscr{X}$, $x \succsim \delta_{e(x)}$. Under the assumptions of Expected Utility Theory (EUT), all forms of diversification are represented by concavity of the utility index and by risk aversion. However, this equivalence fails to hold in model-free settings and under various generalizations of EUT. ${ }^{3}$ Note that in standard theory, a risk averse agent would prefer to diversify because this leads to a reduction of his/her exposure to risk. In contrast, this paper argues that a preference for diversification is a primitive of the model on a similar level as risk aversion.

A note on hedging. Diversification is also closely related to the notion of hedging, yet it is important to distinguish it from the setting of this paper. Schmeidler (1989) introduced the concept of preference for hedging, which captures uncertainty aversion by postulating that for any two acts between which a decision maker is indifferent, the probability mixture of the two acts is preferred to the act itself. Dean and Ortoleva (2017) define hedging over a set of acts as follows. For any three acts $f, g$, and $h$, if a decision maker is indifferent between $f$ and $g$, and $h$ can be obtained as a mixture of $f$ and $g$, then $h$ must be weakly preferred to both. Their main argumemt is that when applied to lotteries, a pessimistic decision maker will exhibit a preference for hedging because it reduces the variance of the utility of outcomes, and when applied to acts, hedging reduces subjective uncertainty by mixing the outcomes that acts return in each state. Diversification may thus be viewed as optimizing hedging behavior. However, there are two important distinctions to make. First, whereas preferences for hedging are defined under subjective uncertainty, this paper's preferences for diversification are in the classical decision theoretic setting under risk, and so uncertainty aversion or reduction does not apply. Second, suppose the decision to diversify under uncertainty comes at a cost, similar to the setting in the experiment in this paper. Then what may seem as an intuitive advantage to hedging or diversification behavior disappears, as the mixture of acts is not necessarily preferred to each act any longer. In other words, optimizing hedging behavior cannot in the case of associated diversification cost any longer explain the decision to diversify.

\subsection{Experimental evidence}

Many of the following studies address anomalous behavior with respect to diversification. They essentially show that individuals prefer variety for the sake of variety, do not like loosing options

Chateauneuf and Tallon (2002), namely that of comonotone diversification, which is essentially convexity of preferences restricted to comonotonic random variables, just as Schmeidler (1989) restricted independence to comonotonic acts. Under this more restrictive type of diversification, any hedging in the sense of Wakker (1990) is prohibited.

${ }^{3}$ The interested reader is referred to De Giorgi and Mahmoud (2016) for a thorough analysis of the choice theoretic foundations of diversification, its definition in some standard economic models, and its relationship to risk aversion. 
in their choices even if they are bad ones, and prefer diversification even when it is ineffective and costly. Suggestions for such "irrational" decision making that have been given include the lack of financial sophistication of the participants, the reliance on biased judgements, cognitive limitations, or inadequate financial knowledge and training. This paper argues that another factor driving the decision making is the intrinsic preference for diversification without other instrumental motives. Loomes (1991) and Rubinstein (2002) show that when subjects are asked to choose among a set of actions, each having some probability of yielding a given prize, subjects tend to violate first-order stochastic dominance by using mixed strategies that mimic the distribution of winning probabilities. Also related is the behavior observed in experiments where subjects are asked to bet on which ball color will be randomly drawn from an urn. Most subjects weakly prefer a bet over an urn that contains balls of each color to a bet over an urn containing balls of only one, randomly determined color (Halevy, 2007). A similar bias towards "excessive diversification" was reported in Read and Loewenstein (1995) where subjects who chose in advance a set of $n$ items to be consumed sequentially at $n$ future dates (one item per period) picked a greater variety of items than subjects who chose $n$ items sequentially, one item at each date of consumption. In another experimental study, Shin and Ariely (2004) show that decision makers often expand efforts to preserve the future viability of current options and that they sometimes value such options more highly than the outcomes they make possible. Their experiments provide initial evidence that the mechanism underlying this diversification tendency is a type of loss aversion and not regret. In a different experimental study, Eliaz and Frechette (2008) reach similar conclusions regarding the diversification bias and the willingness to pay for it. The majority of their experiment subjects were willing to pay to switch from a lottery that pays a prize in only one particular state of nature to a lottery that pays a prize in more than one state, even though the overall distribution over prizes remains the same. Although not directly related to this paper's hypothesis, other experimental studies on diversification in the past have focused on naive diversification as an anomaly (Samuelson and Zeckhauser, 1988; Simonson, 1990; Read and Loewenstein, 1995; Benartzi and Thaler, 2001; Baltussen and Post, 2011; Fernandes, 2013).

Finally, the recent experimental studies of Agranov and Ortoleva (2017) and De Giorgi and Mahmoud (2017) are tangentially related to the idea of intrinsic preference for diversification. Agranov and Ortoleva (2017) suggest that the main driving force behind stochastic choice is the deliberate desire to choose different answers. The experimental study carried out by De Giorgi and Mahmoud (2017) shows that children exhibit preference for diversification in a primitive replication of a portfolio choice problem. The authors suggest that diversification may be an elementary behavioral decision mechanism that did not necessarily and exclusively arise because of a sophisticated understanding of the optimal way to process information in a decision making process; rather, preference for diversification may be a fundamental pre-wired preference that guides the children to make decisions about standalone versus combined choices. 


\section{Experimental design}

\subsection{Hypotheses}

The experiment in this paper was designed to test the following two hypotheses:

(I) Willingness to pay for diversification. Diversification is a concept inherent in a variety of fields, relevant in everyday decision-making, and a prominent concept in models of finance, economics, and evolution. This points towards the idea that diversification is a fundamental driving force intrinsic to decision-making, rather than a consequence of modern economic theories. In particular, the presence of costs associated with diversifying may lead to the conclusion that people choose to diversify simply for the sake of diversification:

(H1) The majority of decision makers are willing to pay something for diversification, even though it would be possible to generate the same expectation of rewards without diversification.

(II) Risk aversion and loss aversion. The notions of risk aversion and loss aversion are closely related. Consider a simple allocation problem between two risky assets with identical payoffs and volatilities and zero correlation. The optimal strategy in the traditional Markowitz portfolio theory is to allocate equally between the two assets. A more general result appeared in Samuelson (1967), where the first formal proof of the following, at the time seemingly well-understood, diversification paradigm is given: "putting a fixed total of wealth equally into independently, identically distributed investments will leave the mean gain unchanged and will minimize the variance." ${ }^{4}$ Assuming that there is no cost associated to diversifying in this simple scenario, the following well-known facts are worth pointing out. First, the expected value of the diversified choice remains unchanged. Second, if the "risk" is taken to be a convex risk measure $\rho: \mathscr{X} \rightarrow \mathbb{R}$, then the overall risk of the diversified choice cannot increase (Föllmer and Schied, 2010).

Loss aversion, on the other hand, reflects the observed behavior that agents are more sensitive to losses than to gains, resulting in a utility function that is steeper for losses than for gains. The phenomenon is well-established, and empirical studies widely support the idea that loss aversion is a major factor in observed risk aversion (Kahneman and Tversky, 1984; List, 2004; Rabin and Thaler, 2001; Rizzo and Zeckhauser, 2004). Indeed, Thaler, Tversky, Kahneman, and Schwartz (1997) show that investors who display loss aversion will be willing to accept more risk if all payoffs are increased enough to eliminate losses. While this paper does not address the causal relationship between loss aversion and risk aversion, it builds on the previous literature by assuming that loss aversion plays a significant role in observed risk aversion, and separately addresses the relationships between risk aversion and loss aversion on one hand and willingness to pay for diversification on the other hand:

(H2) The risk averse and the loss averse decision maker tends to value diversification more compared to the risk seeking decision maker.

\footnotetext{
${ }^{4}$ See Hadar and Russell (1969), Hadar and Russell (1971), Tesfatsion (1976) and Li and Wong (1999) for generalizations of Samuelson's classical result.
} 
Note that, ignoring the link between risk aversion and loss aversion, it is not immediately clear whether a loss averse decision maker would indeed want to diversify in practice, as a formal theory linking loss aversion to diversification does not exist. In some scenarios, the probability of loss may decrease, and in others, loss aversion might promote concentration over diversification. For an example of the former, consider diversifying across two binomial random variables, $X$ and $Y$, each having a payoff of, say, 100 dollars with a probability $p=0.5$, and zero payoff with a probability $1-p=0.5$. Their expectations are $\mathbb{E}(x)=\mathbb{E}(Y)=50$, and their variances are $V(X)=V(Y)=$ 50. The convex combination $Z=\alpha X+(1-\alpha) Y$, for $\alpha \in[0,1]$ has the same expectation and variance, but the probability of a complete loss goes down from 0.5 to 0.25 , which implies that a loss averse decision maker would prefer to diversify in this simplified scenario. On the other hand, Stracca (2002) shows, under the assumptions of choice amongst $n>1$ identically distributed and symmetric sources of risk, that the optimal allocation by a loss averse agent requires risk concentration rather than diversification (provided that the subjective probability of obtaining a perfect hedge is negligible). ${ }^{5}$

\subsection{Design}

The participants engaged in three parts of the experiment addressing the two hypotheses on willingness to pay for diversification, and risk/loss aversion, respectively. The detailed experimental instructions and questions, including screenshots, can be found in Appendix A.

Part 1: The willingness to pay for diversification. Part 1 consisted of 13 questions. In each question, participants were asked to allocate their holding of CHF 100 (i.e. 100 Swiss Francs, which are approximately equivalent to USD 100) to two identical fair dice, D1 and D2, both of which have three sides colored in red and three sides colored in blue. Both dice were then "virtually" rolled, and the decision maker wins the amount he/she assigned to each die if they land on the color red, otherwise they loose the amount assigned to each die.

This game is the basic setup for each of the 13 questions with the cost associated to diversifying across both dice increasing with each question, and the order of the questions was fixed accordingly across all participants. In question 1, there was no cost associated to diversifying. In questions 2 through 10, the participants are told that there is a fixed cost associated with splitting their endowment across the two dice, and that there is no cost associated with allocating the total endowment to only one of the two dice. The fixed costs are CHF 0.10, CHF 0.20, CHF 0.50, CHF 1.00, CHF 2.00, CHF 3.00, CHF 5.00, CHF 8.00, CHF 10.00 for questions 2 through 10, respectively. The last three questions include a variable rather than a fixed cost. The participants are told that the cost of splitting their endowment is a percentage of their allocation to D1, with that percentage being $1 \%, 5 \%$, and $10 \%$ for questions 11,12 , and 13 , respectively. For a summary of the cost structure,

\footnotetext{
${ }^{5}$ To see this, recall the notion of diminishing sensitivity in Cumulative Prospect Theory (CPT), which assumes that agents care more about small shocks with high probability than large shocks with small probability. While classical diversification (which in this case of equal distributions implies equally weighting the $n$ risky assets) reduces the likelihood of events that are distant from the reference point, it may actually increase the noise in its neighborhood. As a consequence, diversification by averaging existing downside risks is utility reducing for the loss averse CPT agent.
} 
refer to Table 1.

Note that this design emulates the definition of preferences for diversification (Definition 1 ) in that the question offers the participants the choice between two equivalent alternatives. When there is no associated cost, perfect diversification across both alternatives is theoretically optimal (Samuelson, 1967). However, as soon as a cost to diversifying is introduced, the diversifying choice is no longer optimal. In practice, choice is usually amongst unequivalent alternatives, such as stocks and bonds in the financial asset market. Here, too, diversification is optimal and not only for the zero cost level. To avoid this confounding effect, the experimental design explicitly focuses on the setup of two equivalent alternatives.

Table 1: Summary of the cost structure associated to each of the 13 identical dice rolling games.

\begin{tabular}{llllllllllllll}
\hline Question & 1 & 2 & 3 & 4 & 5 & 6 & 7 & 8 & 9 & 10 & 11 & 12 & 13 \\
Cost (CHF) & 0.0 & 0.1 & 0.2 & 0.5 & 1.0 & 2.0 & 3.0 & 5.0 & 8.0 & 10.0 & $1 \%$ of D1 & $5 \%$ of D1 & $10 \%$ of D1
\end{tabular}

This approach for measuring diversification preferences based on a multiple price list format is key for the identification in this paper and, more importantly, for ruling out diversification as a mistake of judgement or simple noise. If, for example, the experimental design for eliciting diversification had taken a single cost and showed that, as a result, the economic agent prefers to diversify given that particular arbitrary cost level, a conclusion regarding diversification being a primitive of decision-making, rather than a coincidental mistake, would not have been possible. However, the paper's experimental design allows for a more concrete conclusion. Indeed, the differences in diversification choices as a function of both varying costs and of other behavioral measures (such as risk and loss aversion rule) arguably rule out a simple story of noise and random mistakes. ${ }^{6}$

Part 2: Risk aversion. The second part of the experiment was designed to elicit the participants' risk preferences. The elicitation method of (Gneezy and Potters, 1997) is used as a measure of risk preferences in the context of financial decision-making with real monetary payoffs. The participants were told that they are offered CHF 10 and were given the option of choosing how much of this endowment they would like to keep for sure and how much they would like to allocate to the colors red or blue on a fair 6-sided die with three sides in each color. They were rewarded twice the amount of coupons allocated to the winning color red, otherwise they lose. Because the expected payoff is independent of the chosen allocation, risk aversion is equivalent to choosing a risk-free allocation.

Part 3: Loss aversion. The third and final part of the experiment was designed to examine the relationship between the participants' diversification behavior and a separately elicited loss aver-

\footnotetext{
${ }^{6}$ I thank a referee for raising this issue and for poiting out that whereas pure random mistakes are indeed ruled out, the more standard way of thinking about mistakes in economics and decision theory is not ruled out, such as the idea of mistakes being related to expected losses from these mistakes.
} 
sion parameter. The individuals' preferences were elicited over a series of gambles using multiple price lists. Subjects were asked to make a series of 30 binary decisions, choosing between sure payoffs or risky payoffs with outcomes to be determined by the roll of a fair die with three sides colored in red and three sides colored in blue. The prospect theory setup of Abdellaoui, Bleichrodt, and L'Haridon (2008) is assumed, where the individual evaluates each prospect and chooses the prospect that offers the highest overall utility. The elicitation method consists of three stages. First, utility is elicited on the gain domain, then utility is elicited on the loss domain, and finally the utility on the gain domain and on the loss domain are linked. The set of 30 decisions thus allows an estimation of the three parameters, $\alpha, \beta$, and $\gamma$, of a prospect theory value function for each individual. Formally, this function is given by

$$
v(x)= \begin{cases}x^{\alpha} & \text { if } x \geq 0 \\ -\lambda(-x)^{\beta} & \text { if } x<0\end{cases}
$$

where $\alpha$ is the risk aversion parameter in the gain domain, $\beta$ is the risk aversion parameter in the loss domain, and $\lambda$ is the loss aversion parameter (see also Imas, Sadoff, and Samek (2017) for a similar elicitation method).

To identify the parameter $\alpha$, participants were asked to make a series of choices over gambles where all the outcomes were positive. The multiple price list offered a series of ten decisions between a gamble and a sure amount, where the gamble was constant for each decision and the sure amount gradually increased. The risky gamble involved virtually rolling a fair die with 3 sides colored in red and three sides colored in blue. The payoff was CHF 5 if the die lands on red, otherwise zero. The sure option started at CHF 0.5 in the first decision and increased in CHF 0.5 increments to CHF 5 in the tenth decision. The risk aversion parameter $\beta$ in the loss domain is estimated in a similar manner using a multiple price list with only negative outcomes. In the second set of 10 decisions, subjects made the choice between either a risky option of CHF -5 or CHF 0 based on the roll of the same fair die, or a sure option of CHF - 0.5 through CHF -5 in increments of CHF -0.5. The final multiple price list offered mixed gambles. In the last set of 10 decision problems, subjects made the choice between either a risky option of CHF 5 or CHF - 1 through CHF - 10 in increments of CHF -1 based on the roll of the fair die, or a sure option of CHF 0.

\subsection{Subjects, reward structure, and procedure}

The experiment was conducted online and programmed in oTree in the form a survey. The link to the survey was sent to participating students through the Behavioral Laboratory of the University of St. Gallen via email, and so the participants could take part in the experiment at their own convenience without any location or time restrictions. The experiment link was technically set up so that each participant could only take part in the experiment a single time. Moreover, as the survey was in the form of a sequence of choice questions, the participants had to make sequential decisions without the option of returning to a previous question and editing their answer.

Each question and game was explained carefully one at a time. The participants then filled in their 
choice(s) and could only then proceed to the next question, without the possibility of returning to alter their answers. All three choice questions on willingness to pay for diversification, risk aversion and loss aversion were rewarded. The participants were told that only one randomly selected choice alternative from Question 1 on the willingness to pay for diversification would be rewarded and so strategic hedging between choice alternatives in the multiple choice list is avoided. The outcome of the virtual dice-rolling gambles was not revealed after each question. At the end of the experiment, the final page revealed the outcomes to each of the three questions and the total potential reward based on the participant's choices. This helped avoid satiation. To reward the students, they were told that only a randomly selected number of them (precisely 10 participants) were to be rewarded. Often times due to budget constraints, payment schemes with random components are commonly used in experiments on individual decision-making and there is solid evidence showing that these schemes do not change behavior (Starmer, 1991; Cubitt, 1998; Hey and Lee, 2005). Considering that the experiment took a maximum of 15 minutes to complete, the stake size was nevertheless quite sizable. The winners were selected using a random number generator once the experiment was finalized and no more participants had access to the online survey link. To be able to distribute the rewards following completion of the experiment, each participant was assigned a unique random number at the start of the experiment and was given the voluntary option to enter the personal email address at the end of the experiment.

The experiment was described to the participants as being for the purpose of a research study in decision-making at the University of St. Gallen in Switzerland, where the author was based at the time of the experiment. The exact details and purpose of the study were not revealed. In particular, any terminology relating to financial decisions, diversification, risk aversion, loss aversion, portfolios and investments were never used. A total of 241 students completed the online survey. Gender, level of study (Bachelor or Master), and subject of study (Economics/Finance or other subjects) were recorded for each participant. Of the 241 participants, 155 were male, and 85 female; 116 were students of economics or finance, and 124 studied other subjects; 146 were Bachelor students, and 95 Masters students. The anonymity of each participant was preserved as no names were required.

\section{Results}

\subsection{The willingness to pay for diversification}

Table 2 displays the percentage of participants choosing to either diversify by splitting their endowment ("Div"), or not diversifying at all by assigning their entire endowment to one option only ("Conc.") for each of the 13 questions reflecting 13 different cost structures (recall Table 1). The following observations emerge.

When there is no cost associated with diversifying, the large majority of about $86 \%$ chose to split their allocations. As the cost increases, this fraction decreases steadily, for both the fixed and the variable cost. Thus, when the cost is "small enough", there is a degree of willingness to pay for 
Table 2: Willingness to pay for diversification. Overview of the percentage of participants diversifying for each of the fixed and variable cost choice questions. "Div." refers to (\%) participants choosing to diversify for the given cost level (fixed cost in CHF, variable cost in \% of allocation), and "Conc." refer to (\%) participants choosing to concentrate their allocation in one option rather than to diversify. The table also reports $p$ values for a binomial majority test for the null hypothesis that less than $50 \%$ of participants choose to diversify against the alternative that the majority of participants ( $\geq 50 \%)$ diversify their endowment across both dice. The $p$-values are reported with rejections at a $5 \%$ confidence level indicated by *.

\begin{tabular}{|c|c|c|c|c|c|c|c|c|c|c|}
\hline Cost (CHF) & 0.0 & 0.1 & 0.2 & 0.5 & 1.0 & 2.0 & 3.0 & 5.0 & 8.0 & 10.0 \\
\hline Div. & 86.31 & 68.88 & 68.88 & 69.29 & 63.49 & 60.58 & 56.43 & 43.15 & 34.44 & 28.63 \\
\hline Conc. & 13.69 & 31.12 & 31.12 & 30.71 & 36.51 & 39.42 & 43.57 & 56.85 & 65.56 & 71.37 \\
\hline$p$-value & $(0.00) *$ & $(0.00)^{*}$ & $(0.00) *$ & $(0.00) *$ & $(0.00) *$ & $(0.00) *$ & $(0.02) *$ & $(0.98) *$ & $(1.00) *$ & $(1.00) *$ \\
\hline Variable Cost: & $1 \%$ & $5 \%$ & $10 \%$ & & & & & & & \\
\hline Div. & 54.77 & 46.89 & 34.02 & & & & & & & \\
\hline Conc. & 45.23 & 53.11 & 65.98 & & & & & & & \\
\hline$p$-value & $(0.04) *$ & $(0.82)$ & $(1.00)$ & & & & & & & \\
\hline
\end{tabular}

diversification. The turning point occurs at the CHF 5.0 mark, when the majority of participants chose concentration over diversification. This cost level corresponds to $5 \%$ of their entire initial holding of CHF 100 and can be interpreted as an estimator for how much an economic agent is willing to pay for diversification. The binomial majority test, with significance levels reported in Table 2, is consistent with this interpretation that up to a fixed cost of CHF 5\%, the majority of respondents prefer to diversify. These results confirm the hypothesis that there is a strictly positive, albeit small, value attached to the notion of diversifying, which is inconsistent with classical portfolio choice and expected utility theory. Note that, as in most laboratory experiments, the stakes are relatively low, and so one might expect this percentage to decrease in a real-world setting when the stakes are higher. However, the conjecture that people would pay a positive, albeit small, amount to diversify is likely to translate to practice.

This evidence points towards the paper's main concept of willingness to pay for diversification. This insight has several implications regarding our understanding of the notion of diversification in economics. First, rather than being an optimization methodology towards the end of maximizing utility, diversification for the sake of diversification is valued. In other words, people have an intrinsic preference for diversification that is independent of instrumental motives. Second, this intrinsic preference to diversify is responsive to cost. Third, whereas the economic literature has typically thought of this behavior as a mistake since it is suboptimal in the theoretical sense, this behavior is not a mistake from the perspective of the individual decision maker, as it is driven by an inherent preference that is responsive to costs and benefits.

Note that the results of Table 2 for the final three variable cost allocation problems are inconsistent 
Figure 1: Distribution of individual willingness-to-pay for diversification.

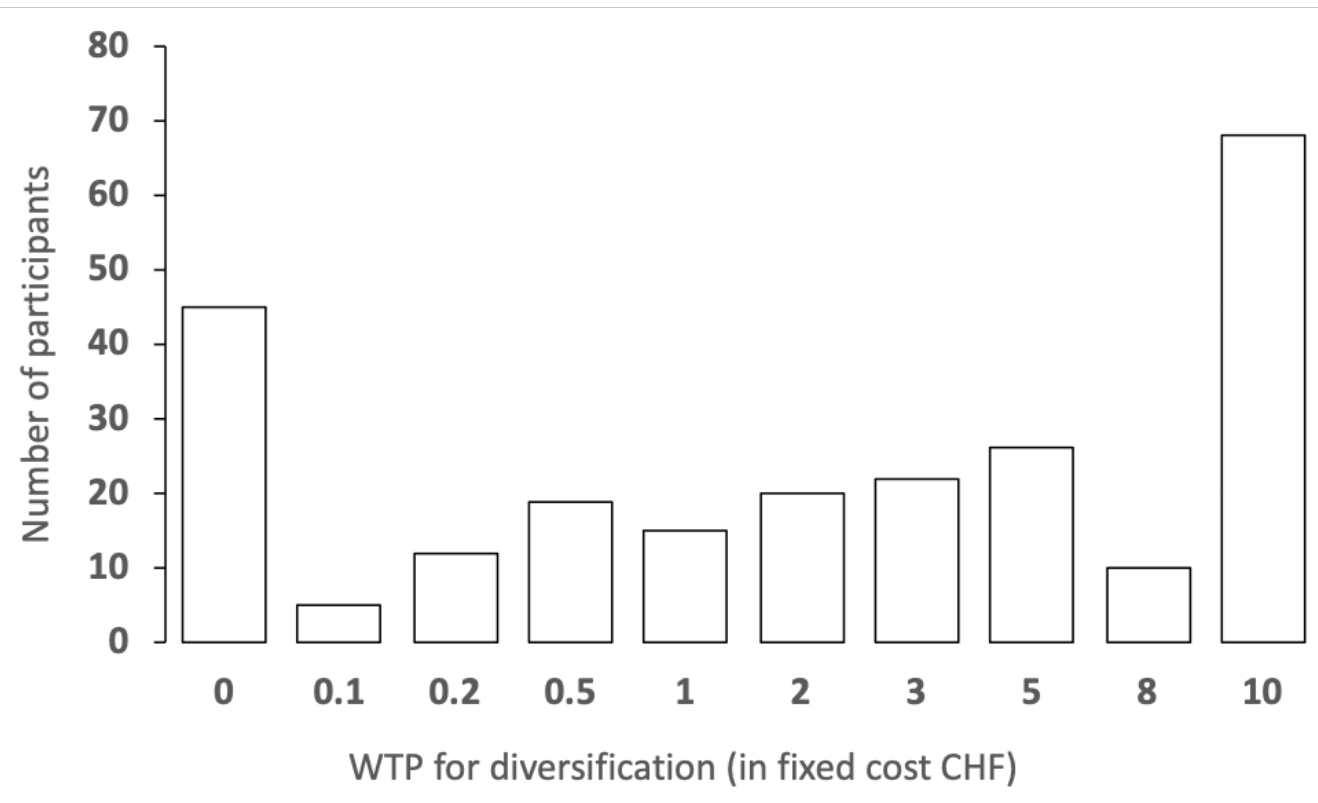

with the fixed cost results. Recall that the variable cost is given by a percentage of the allocation to one die and not of the entire endowment. This means that for naive diversifiers, $1 \%$ corresponds to a fixed cost of CHF 0.5, 5\% corresponds to CHF 2.5, and 10\% amounts to CHF 5.0. Moreover, the binomial majority test passes only for the smallest variable cost of $1 \%$.

Finally, a different dimension is explored by looking at the type of allocation strategies applied across all costs by each individual rather than the dominating allocations across all participants for each level of cost. Figure 1 displays the distribution of willingness-to-pay for diversification across the 10 fixed cost options at the individual level. For each respondent, the individual willingnessto-pay (WTP) is defined as the cost level in the increasing price list at which he/she switches from a diversifying strategy to not diversifying at all. It is the maximum value beyond which diversification is perceived as too expensive. A WTP of CHF 0 indicates that the individual chooses to diversify only if it comes with no associated cost. The mean and median WTP across respondents are CHF 4.2 and CHF 3.0, respectively. The distribution of Figure 1 implies a heterogeneity in the WTP for diversification, which can be interpreted as the magnitude of the individual valuation of diversifying. The core of the distribution (53.5\%) lies between the CHF 0.1 and CHF 8 cost level. Noteworthy is the largest concentration at the highest cost level of CHF 10, which shows that over $28 \%$ of respondents have a very high level of WTP and thus always chose to diversify regardless of cost. Overall, approximately $26 \%$ of individuals do not diversify when there is a cost associated with splitting the allocation. This means that the majority of $74 \%$ display a willingness to pay for diversification either regardless of (fixed) cost or for some cost level. This observation is consistent with the previous findings from Table 2 and provides further support for the first hypothesis of this paper. 


\subsection{Risk aversion}

To determine the participants' risk attitudes, their allocations from the second part of the experiment were used, which essentially represents an allocation task between a risk-free asset (keeping the entire endowment of CHF 10 for sure) and a risky asset (playing the dice rolling game). Because in this question the expected payoff is independent of the allocation of their endowment, risk averse individuals are those choosing the risk-free payoff, while less risk averse individuals are those taking on some level of risk. According to this classification, participants were divided into strongly risk averse individuals (199 individuals or 82\%) and less risk risk averse (42 individuals or $18 \%$ ), and the respective diversification preferences under the various cost schemes were analyzed for each group.

Tables 3 and 4 report the main results on the relation between diversification and risk attitude. The following observations emerge. First, for non-zero costs of diversification, the HerfindahlHirschman Index (HHI), which is a statistical dispersion measure of inequality of allocation weights, is consistently lower for the strongly risk averse participants than it is for the less risk averse ones, and significantly so for the lower end of the cost spectrum (fixed costs of CHF 0.1 through CHF 3.0, and variable cost of 1\%) (see Table 3). Strongly risk averse individuals were thus overall closer to perfect diversifiers compared to their less risk averse counterparts as long as the costs associated are low enough. Note that for the higher cost schemes, the hypothesis that average allocations are equal regardless of risk attitude cannot be rejected. These results are consistent with classical economic theory which stipulates that diversification and risk aversion are closely related and, under certain conditions, equivalent notions.

Next, Table 4 reports, for each cost level, the percent of participants diversifying for each risk attitude. Each entry indicates, for a given cost level, the percentage of all strongly risk averse (resp. less risk averse) individuals that choose a given allocation scheme. The first row of Table 4 shows that the percentage of individuals choosing to diversify is consistently higher among the strongly risk averse group compared to the less risk averse group across all non-zero fixed cost schemes. The reverse is true for the non-diversified allocation: consistent across all fixed cost schemes, more of the less risk averse (in percentage terms) are choosing to fully concentrate their holdings in one choice compared with the percentage of strongly risk averse individuals. Similar observations hold for the variable cost allocations (except for the $10 \%$ cost scheme). To evaluate the statistical significance of these frequency differences amongst the two risk attitude groups, a chi-squared homogeneity test is used to test the null hypothesis that strongly risk averse and less risk averse allocation frequencies are equal and that thus any observed difference between the two categorical sets of individuals arose by chance. Table 5 reports the test statistics for a chisquared test of homogeneity to determine whether frequency counts are distributed identically across the different risk attitude groups. Up until a cost level of 5\% for both fixed and variable cost schemes, the null hypothesis that each risk attitude has the same proportion of diversifiers is rejected, implying that the differences in percent diversifiers for each risk attitude group discussed above are statistically significant.

Finally, the relationship between willingness to pay for diversification and risk attitude is investi- 
Table 3: Risk attitude and level of diversification. Summary statistics for the overall diversification for each of the 13 cost choice questions. Diversification is measured using the Herfindahl-Hirschman Index (HHI) statistical dispersion measure of inequality. The normalized Herfindahl-Hirschman Index for asset weights $\alpha_{i}$ for $i=1, \rightarrow n$ is given by $\operatorname{HHI}\left(\alpha_{1}, \ldots, \alpha_{n}\right)=\frac{n \sum_{i=1}^{n} \alpha_{i}^{2}-1}{n-1}$. Under HHI, naive diversification implies that $\mathrm{HHI}=0$. The less equal the allocation weights, the higher the HHI value, reaching its maximum of $\mathrm{HHI}=1$ for total concentration in one option. The table also reports $p$-values for the null hypothesis that average allocations, as measured by HHI, are equal for the risk averse and the risk seeking categories. This hypothesis is tested using the Mann-Whitney-Wilcoxon test (Mann and Whitney, 1947), and the p-values are reported with rejections at a $5 \%$ confidence level indicated by *.

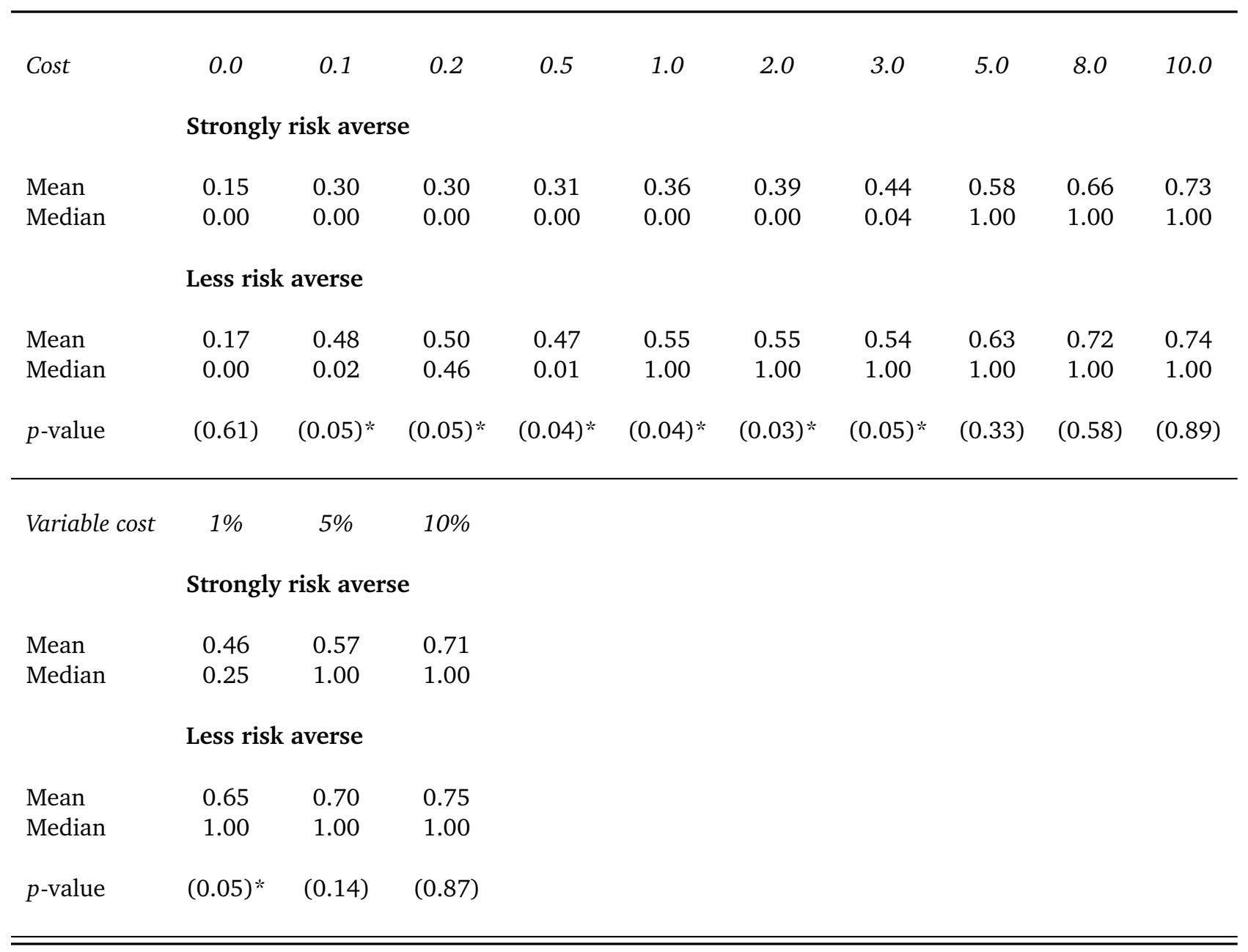


Table 4: Risk attitude and willingness to pay for diversification. Overview of percent of participants diversifying according to risk aversion. The table also reports $p$-values for a binomial majority test for the null hypothesis that less than $50 \%$ of participants within a given risk attitude category choose to diversify against the alternative that the majority of participants $(\geq 50 \%$ ) diversify their endowment across both dice. The $p$-values are reported with rejections at a 5\% confidence level indicated by *.

\begin{tabular}{|c|c|c|c|c|c|c|c|c|c|c|}
\hline Fixed cost: & 0.0 & 0.1 & 0.2 & 0.5 & 1.0 & 2.0 & 3.0 & 5.0 & 8.0 & 10.0 \\
\hline \multicolumn{11}{|c|}{ Diversified allocation } \\
\hline Strongly risk averse & $\begin{array}{c}86.43 \\
(0.00)^{*}\end{array}$ & $\begin{array}{c}71.86 \\
(0.00)^{*}\end{array}$ & $\begin{array}{c}72.36 \\
(0.00)^{*}\end{array}$ & $\begin{array}{c}72.36 \\
(0.00) *\end{array}$ & $\begin{array}{c}66.83 \\
(0.00)^{*}\end{array}$ & $\begin{array}{c}63.32 \\
(0.00)^{*}\end{array}$ & $\begin{array}{c}58.29 \\
(0.01)^{*}\end{array}$ & $\begin{array}{l}44.22 \\
(0.94)\end{array}$ & $\begin{array}{l}35.68 \\
(1.00)\end{array}$ & $\begin{array}{l}29.15 \\
(1.00)\end{array}$ \\
\hline Less risk averse & $\begin{array}{c}85.71 \\
(0.00)^{*}\end{array}$ & $\begin{array}{l}54.76 \\
(0.12)\end{array}$ & $\begin{array}{l}52.38 \\
(0.32)\end{array}$ & $\begin{array}{l}54.76 \\
(0.22)\end{array}$ & $\begin{array}{l}47.62 \\
(0.56)\end{array}$ & $\begin{array}{l}47.62 \\
(0.56)\end{array}$ & $\begin{array}{l}47.62 \\
(0.56)\end{array}$ & $\begin{array}{l}38.10 \\
(0.92)\end{array}$ & $\begin{array}{l}28.57 \\
(1.00)\end{array}$ & $\begin{array}{l}26.19 \\
(1.00)\end{array}$ \\
\hline Variable cost: & $1 \%$ & $5 \%$ & $10 \%$ & & & & & & & \\
\hline \multicolumn{11}{|c|}{ Diversified allocation } \\
\hline Strongly risk averse & $\begin{array}{c}58.29 \\
\left(0.05^{*}\right)\end{array}$ & $\begin{array}{l}49.76 \\
(0.50)\end{array}$ & $\begin{array}{l}34.67 \\
(1.00)\end{array}$ & & & & & & & \\
\hline Less risk averse & $\begin{array}{l}38.10 \\
(0.92)\end{array}$ & $\begin{array}{l}33.33 \\
(0.98)\end{array}$ & $\begin{array}{l}30.95 \\
(0.99)\end{array}$ & & & & & & & \\
\hline
\end{tabular}

Table 5: Risk attitude and chi-squared homogeneity test. Chi-squared test statistics applied to categorical sub-groups according to risk attitude. For each of the 13 cost schemes, the null hypothesis that each risk attitude group (strongly risk averse versus less risk averse) has the same proportion of observations is tested against the hypothesis that they differ.

\begin{tabular}{|c|c|c|c|c|c|c|c|c|c|c|}
\hline $\begin{array}{l}\text { Fixed cost } \\
p \text {-value }\end{array}$ & $\begin{array}{l}0.0 \\
(0.53)\end{array}$ & $\begin{array}{l}0.1 \\
(0.06)^{*}\end{array}$ & $\begin{array}{l}0.2 \\
(0.01) *\end{array}$ & $\begin{array}{l}0.5 \\
(0.05)^{*}\end{array}$ & $\begin{array}{l}1.0 \\
(0.04) *\end{array}$ & $\begin{array}{l}2.0 \\
(0.04)^{*}\end{array}$ & $\begin{array}{l}3.0 \\
(0.15)\end{array}$ & $\begin{array}{l}5.0 \\
(0.63)\end{array}$ & $\begin{array}{l}8.0 \\
(0.65)\end{array}$ & $\begin{array}{l}10.0 \\
(0.75)\end{array}$ \\
\hline $\begin{array}{l}\text { Variable cost } \\
p \text {-value }\end{array}$ & $\begin{array}{l}1 \% \\
(0.04) *\end{array}$ & $\begin{array}{l}5 \% \\
(0.05)^{*}\end{array}$ & $\begin{array}{l}10 \% \\
(0.67)\end{array}$ & & & & & & & \\
\hline
\end{tabular}


gated by looking at each individual cost scheme and whether the majority of individuals within a given risk attitude group chooses to diversify. Table 4 reports $p$-values for a binomial majority test for the null hypothesis that less than $50 \%$ of participants choose to diversify against the alternative that the majority of participants $(\geq 50 \%)$ diversify their endowment across both dice. When there is no cost associated with diversifying, the large majorities of both less risk averse (85.71\%) and strongly risk averse (86.43\%) chose to split their allocations. As the cost increases this fraction decreases steadily, for both the fixed and the variable cost across both risk attitude categories. However, for the less risk averse, the majority diversifies only when there are no associated costs. One may thus conclude that they are unwilling to pay for diversification. By contrast, the strongly risk averse participants do exhibit a degree of willingness to pay for diversification when the cost is "small enough". The turning point occurs at the CHF 5.0 mark, when the significant majority, as confirmed by the $p$-value for the binomial test, chose concentration over diversification. Interestingly, the results for the three variable cost schemes are once again inconsistent with the fixed cost answers. Indeed, only in the risk averse subject group did the majority choose to diversify under the lowest variable cost of $1 \%$.

In summary, the results of the second part of the experiment demonstrate that there is a significant relationship between risk aversion, level of diversification, and willingness to pay for diversification. More precisely: (i) very risk averse individuals tend to have higher levels of diversification as reported by HHI values compared to less risk averse individuals; (ii) the majority of risk averse individuals diversify for most cost levels; and thus (iii) when the cost is small enough, strongly risk averse individuals are willing to pay for diversification, whereas the less risk averse only diversify when there are no associated costs.

\subsection{Loss aversion}

In this Section, the relationship between loss aversion, diversification, and willingness to pay for diversification is investigated based on the third and final question of the experiment. Here, the choice questions consist of multiple choice lists designed to elicit loss aversion. The pattern generally observed is that subjects start out by choosing the gamble and then switch to the sure outcome when the sure outcome becomes large enough. The choice at which a subject switches in the first set of 10 decision problems is taken as the indifference point between the lottery and the sure outcome. Since all outcomes are positive, the formulation of the decision problem does not involve $\beta$ or $\lambda$, and it is thus straightforward to estimate the parameter $\alpha$. Similarly, to estimate $\beta$, the decision problem does not involve $\alpha$ or $\lambda$, so $\beta$ can be separately identified. To estimate the loss aversion parameter $\lambda$, the final multiple price list with mixed gambles is used by setting up the decision problem at the indifference point and using the risk aversion parameters $\alpha$ and $\beta$ that were estimated separately from the first two multiple price lists.

A total of 34 individuals who either exhibited extreme risk attitudes by never switching or inconsistent attitudes by switching back and forth between risky gambles and sure outcomes were excluded from the analysis, leaving the remainder of 207 participants. The average risk aversion parameters are $\bar{\alpha}=0.79$ in the domain of gains, and $\bar{\beta}=0.94$ in the domain of losses, which is consistent with 


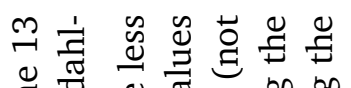

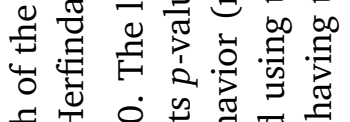

氜要

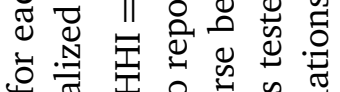

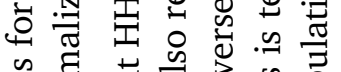

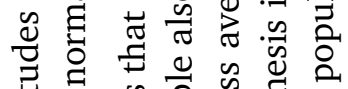

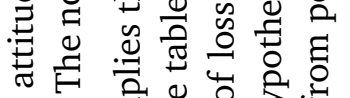

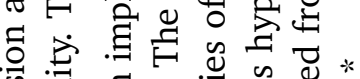

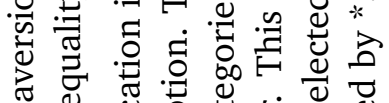

ब छ

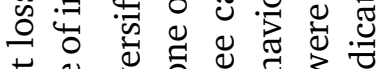

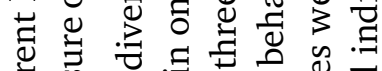

党

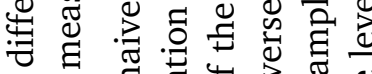

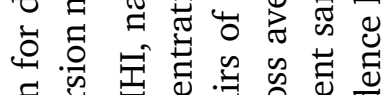

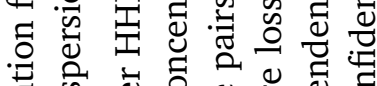

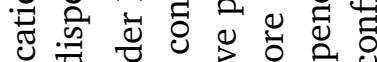

需 元

एँ

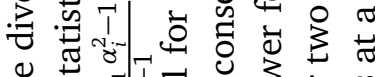

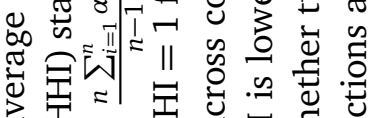

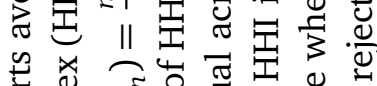

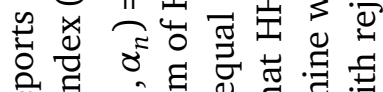

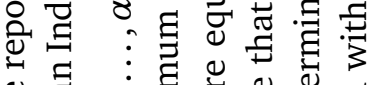

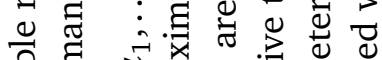

क्षै

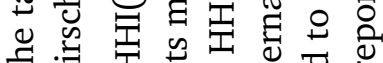

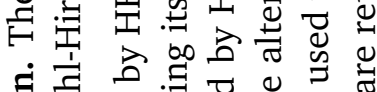

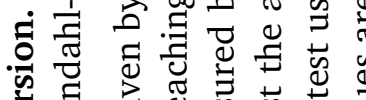

品

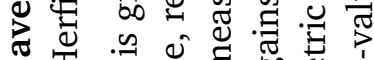

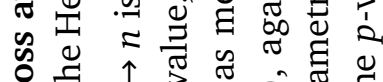

o

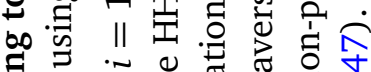

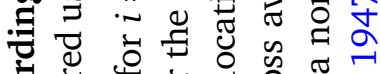

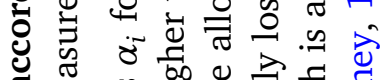

ॠ

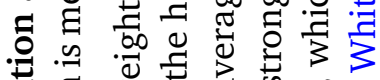

ठ

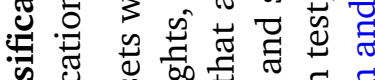

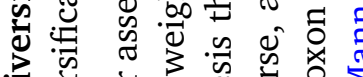

敢

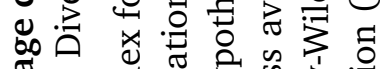

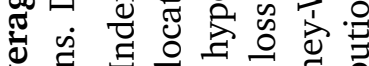

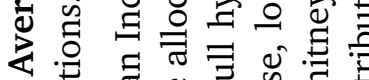

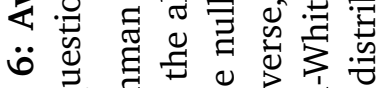

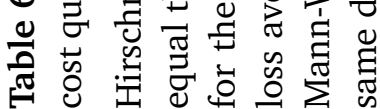

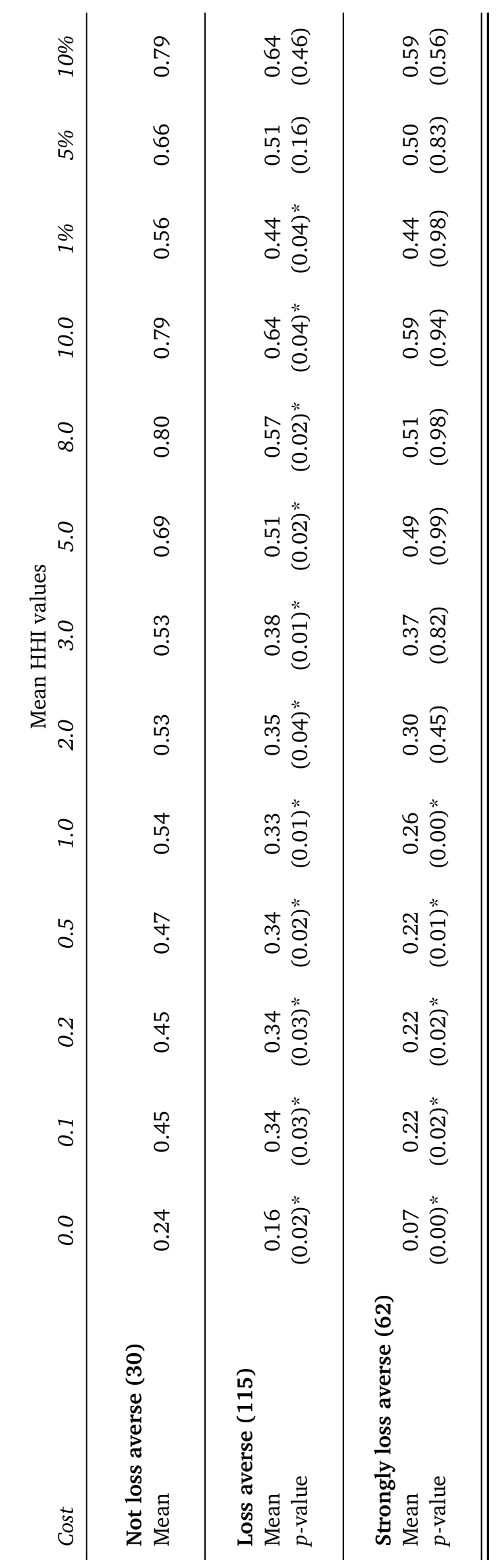


Table 7: Loss aversion and chi-squared homogeneity test. Chi-squared test statistics applied to categorical sub-groups according to loss aversion. For each of the 13 cost schemes, the null hypothesis that each loss aversion group (loss averse, not loss averse, strongly loss averse) has the same proportion of observations is tested against the hypothesis that they differ.

\begin{tabular}{|c|c|c|c|c|c|c|c|c|c|c|}
\hline $\begin{array}{l}\text { Fixed cost } \\
p \text {-value }\end{array}$ & $\begin{array}{l}0.0 \\
(0.74)\end{array}$ & $\begin{array}{l}0.1 \\
(0.05) *\end{array}$ & $\begin{array}{l}0.2 \\
(0.01) *\end{array}$ & $\begin{array}{l}0.5 \\
(0.04)^{*}\end{array}$ & $\begin{array}{l}1.0 \\
(0.04) *\end{array}$ & $\begin{array}{l}2.0 \\
(0.05) *\end{array}$ & $\begin{array}{l}3.0 \\
(0.32)\end{array}$ & $\begin{array}{l}5.0 \\
(0.43)\end{array}$ & $\begin{array}{l}8.0 \\
(0.67)\end{array}$ & $\begin{array}{l}10.0 \\
(0.81)\end{array}$ \\
\hline $\begin{array}{l}\text { Variable cost } \\
p \text {-value }\end{array}$ & $\begin{array}{l}1 \% \\
(0.05) *\end{array}$ & $\begin{array}{l}5 \% \\
(0.05) *\end{array}$ & $\begin{array}{l}10 \% \\
(0.89)\end{array}$ & & & & & & & \\
\hline
\end{tabular}

prospect theory claims that the value function is steeper for losses than it is for gains (Kahneman and Tversky, 1984). The average loss aversion parameter $\lambda$ in the sample is 1.92 , whereas the median is 1.67 , which corresponds to significant loss aversion similar to what has been documented in previous work (Kahneman and Tversky, 1992; Abdellaoui, Bleichrodt, and L'Haridon, 2008). In the following analysis, individuals are divided into those that are not loss averse (30 individuals), those that are loss averse with loss aversion values $\lambda \in(1,2]$ (115 individuals), and those that are "strongly" loss averse with $\lambda \in(2,4]$ (62 individuals).

Table 6 reports diversification levels as measured by HHI for each cost level and each of the three loss aversion categories. Overall, across all loss aversion categories, the higher the cost, the higher the HHI value, and thus the lower the level of diversification. Along the loss aversion dimension, the higher the level of loss aversion, the lower the HHI values and thus the higher the level of diversification. Table 6 also reports $p$-values for the null hypothesis that average allocations, as measured by HHI, are equal across consecutive pairs of the three categories of loss averse behavior (not loss averse, loss averse, and strongly loss averse), against the alternative that $\mathrm{HHI}$ is lower for more loss averse behavior. The first row of $p$-values thus compares not loss averse average allocations to loss averse average allocations, and the second row of $p$-values compares loss aversion to strong loss aversion. Note that the difference between mean HHI values is significant across most cost schemes (except for the highest two variable costs) when looking at individuals that are not loss averse and those that are loss averse. The significance is lower when comparing regular and strong loss aversion.

To evaluate the statistical significance of these frequency differences amongst the different loss aversion groups, a chi-squared homogeneity test is used to test the null hypothesis that loss averse, not loss averse and strongly loss averse allocation frequencies are equal and that thus any observed difference between the three categorical sets of loss aversion level arose by chance. Table 7 reports the test statistics for a chi-squared test of homogeneity to determine whether frequency counts are distributed identically across the different loss aversion groups. Once again, up until a cost level of $5 \%$ for both fixed and variable cost schemes, the null hypothesis that each loss aversion level has the same proportion of diversifiers is rejected, implying that the differences in percent diversifiers for each of these subgroups discussed above are statistically significant. 
Next, Table 8 reports, for each cost level, the percent of individuals diversifying within each loss aversion group. Within each cost level, the more loss averse a group of individuals, the higher the percentage of individuals within that group choosing to diversify. In terms of willingness to pay for diversification, only for the zero-cost case can one observe that the majority of individuals that are not loss averse diversify. For all remaining cost levels, the percentage of diversifiers within that group is either less than (for higher cost levels) or approximately equal to (for lower cost levels) the percentage of non-diversifiers. The willingness to pay increases for stronger loss aversion, where the cost turning point occurs once again at the CHF 5.0 mark compared to the much lower CHF 0.5 cost turning point for participants that have lower loss aversion parameter values. The binomial majority test, whose $p$-values are reported in Table 8, provides the statistical significance of these values, confirming the hypothesis that up to a certain value, loss averse and strongly loss averse individuals choose to diversify. The value attached to diversifying is higher for more loss averse individuals. Note again the inconsistency between the results for fixed and variable costs, as under none of the variable cost levels does the majority of any of the three loss aversion groups diversify.

\section{Concluding remarks}

In order to understand whether there is an intrinsic preference for diversification, diversification preferences are elicited in an experimental study through a sequence of simple gambles replicating a portfolio choice problem. The cost of diversifying is varied in each question, starting from zero cost and going up incrementally to the equivalent of about $10 \%$ of the initial holding. The value of diversification is estimated to be at $5 \%$ of the initial endowment of CHF 100 . This evidence points towards the paper's main concept of willingness to pay for diversification. The experiments further show that risk averse and loss averse individuals are willing to pay more for diversification.

This insight has several implications regarding our understanding of the notion of diversification in economics. First, people seem to have a fundamental preference for diversification that is independent of instrumental motives. Second, this preference to diversify is responsive to cost. Third, whereas the economic literature has typically thought of this behavior as a mistake since it is suboptimal in the theoretical sense, this behavior is not a mistake from the perspective of the individual decision maker, as it is driven by an inherent preference that is responsive to costs and benefits. In particular, the willingness to pay for diversification may explain instances of irrational diversification observed in practice. For example, Eliaz and Frechette (2008) document a systematic bias towards "false diversification" in decision-making under risk, in which the majority of subjects are willing to pay to switch from a lottery that pays a prize in only one particular state of nature to a lottery that pays a prize in more than one state even though the distribution over prizes remains the same. The authors cannot find a model-based explanation for this seemingly irrational behavior, and they conjecture that it may be a consequence of case-based decision-making. The closely related willingness-to-pay found in this paper's experiments are consistent with the findings of Eliaz and Frechette (2008) and provides a different explanation of their observed "false diversification" in terms of an intrinsic preference rather than an instance of some model-based decision-making 
Table 8: Loss aversion and willingness to pay for diversification. Overview of percent of participants diversifying categorized according to loss aversion. The table also reports $p$-values for a binomial majority test for the null hypothesis that less than $50 \%$ of participants within a given loss aversion category choose to diversify against the alternative that the majority of participants ( $\geq 50 \%)$ diversify their endowment across both dice. The $p$-values are reported with rejections at a $5 \%$ confidence level indicated by *.

\begin{tabular}{|c|c|c|c|c|c|c|c|c|c|c|}
\hline Fixed cost: & 0.0 & 0.1 & 0.2 & 0.5 & 1.0 & 2.0 & 3.0 & 5.0 & 8.0 & 10.0 \\
\hline \multicolumn{11}{|c|}{ Percent of participants diversifying } \\
\hline Not loss av. & $\begin{array}{c}76.67 \\
(0.00) *\end{array}$ & $\begin{array}{l}53.67 \\
(0.12)\end{array}$ & $\begin{array}{l}53.67 \\
(0.41)\end{array}$ & $\begin{array}{l}53.67 \\
(0.38)\end{array}$ & $\begin{array}{l}50.00 \\
(0.45)\end{array}$ & $\begin{array}{l}50.00 \\
(0.57)\end{array}$ & $\begin{array}{l}50.00 \\
(0.66)\end{array}$ & $\begin{array}{l}33.33 \\
(0.91)\end{array}$ & $\begin{array}{l}23.33 \\
(1.00)\end{array}$ & $\begin{array}{l}23.33 \\
(1.00)\end{array}$ \\
\hline Loss av. & $\begin{array}{c}83.10 \\
(0.00)^{*}\end{array}$ & $\begin{array}{c}61.97 \\
(0.02)^{*}\end{array}$ & $\begin{array}{c}60.56 \\
(0.02) *\end{array}$ & $\begin{array}{c}61.97 \\
(0.02)^{*}\end{array}$ & $\begin{array}{l}52.11 \\
(0.32)\end{array}$ & $\begin{array}{l}46.48 \\
(0.29)\end{array}$ & $\begin{array}{l}43.66 \\
(0.33)\end{array}$ & $\begin{array}{l}30.99 \\
(0.92)\end{array}$ & $\begin{array}{l}22.54 \\
(1.00)\end{array}$ & $\begin{array}{l}15.49 \\
(1.00)\end{array}$ \\
\hline Str. loss av. & $\begin{array}{c}96.15 \\
(0.00)^{*}\end{array}$ & $\begin{array}{c}80.77 \\
(0.00)^{*}\end{array}$ & $\begin{array}{c}80.77 \\
(0.00)^{*}\end{array}$ & $\begin{array}{c}80.77 \\
(0.00)^{*}\end{array}$ & $\begin{array}{c}76.92 \\
(0.01)^{*}\end{array}$ & $\begin{array}{c}73.08 \\
(0.01)^{*}\end{array}$ & $\begin{array}{c}65.38 \\
(0.02) *\end{array}$ & $\begin{array}{l}42.31 \\
(0.89)\end{array}$ & $\begin{array}{l}30.77 \\
(1.00)\end{array}$ & $\begin{array}{l}23.08 \\
(1.00)\end{array}$ \\
\hline Variable cost: & $1 \%$ & $5 \%$ & $10 \%$ & & & & & & & \\
\hline \multicolumn{11}{|c|}{ Percent of participants diversifying } \\
\hline Not loss av. & $\begin{array}{l}53.33 \\
(0.58)\end{array}$ & $\begin{array}{l}46.67 \\
(0.93)\end{array}$ & $\begin{array}{l}33.33 \\
(1.00)\end{array}$ & & & & & & & \\
\hline Loss av. & $\begin{array}{l}45.07 \\
(0.71)\end{array}$ & $\begin{array}{l}35.21 \\
(0.87)\end{array}$ & $\begin{array}{l}25.35 \\
(1.00)\end{array}$ & & & & & & & \\
\hline Str. loss av. & $\begin{array}{l}69.23 \\
(0.21)\end{array}$ & $\begin{array}{l}53.85 \\
(0.63)\end{array}$ & $\begin{array}{l}26.92 \\
(0.99)\end{array}$ & & & & & & & \\
\hline
\end{tabular}


bias. As another example, consider the "diversification bias" documented by Read and Loewenstein (1995) in the context of consumption, which provides experimental evidence that if people make combined choices of quantities of goods for future consumption, they choose more variety than if they make separate choices immediately preceding consumption. On the basis of results of further experiments, the authors then conclude that the diversification bias is largely attributable to two mechanisms, that of time contraction, which is the tendency to compress time intervals and treat long intervals as if they were short, and that of choice bracketing, which is the tendency to treat choices that are framed together differently from those that are framed apart. I conjecture that their documented variety seeking may also be attributed to a third mechanism representing an intrinsic preference for diversification. This is also in line with research in the marketing literature, which finds that consumers often seek variety "for the sake of variety" (Kahn and Ratner, 2005). Future experimental work is needed to clearly establish this hypothesized link between this paper's intrinsic diversification preferences, the "false diversification" paradigm of Eliaz and Frechette (2008), and the "diversification bias" of Read and Loewenstein (1995).

Taking a behavioral viewpoint, I thus contend that diversification is an independent driving force of behavior that is not necessarily a consequence of knowledge of financial models, and - at least partly - a fundamental preference with deep roots that is responsive to cost. Indeed, many other behavioral preferences, such as selfishness, cooperation and risk aversion, have been argued as being elementary and perhaps intrinsic to human nature. Moreover, diversifying behavior known as bet-hedging has been widely documented in other species (Hopper, 1999; Olofsson, Ripa, and Jonzén, 2009; Starrfelt and Kokko, 2012; Rajon, Desouhant, Chevalier, Debias, and Menu, 2014; Ackerman, Maner, and Carpenter, 2016). Therefore, what modern theory postulates as being anomalous diversification may have pre-wired behavioral roots. This paper's insights may thus support a new theoretical foundation for the investigation of diversification.

\section{References}

Abdellaoui, M., H. Bleichrodt, And O. L'HARIdon (2008): "A Tractable Mehotd to Measure Utility and Loss Aversion under Prospect Theory," Journal of Risk and Uncertainty, 36(245).

Ackerman, J. M., J. K. Maner, and S. M. Carpenter (2016): “Going All In: Unfavorable Sex Ratios Attenuate Choice Diversification," Psychological Science, 27(6).

Agranov, M., And P. Ortoleva (2017): "Stochastic Choice and Preferences for Randomization," Journal of Political Economy, 125(1), 40-68.

Baltussen, G., And T. Post (2011): "Irrational Diversification: An Examination of the Portfolio Construction Decision," Journal of Financial and Quantitative Analysis, 46(5).

Benartzi, S., And R. Thaler (2001): "Naive Diversification Strategies in Defined Contribution Saving Plans," American Economic Review, 91, 79-98. 
Bernoulli, D. (1738): "Exposition of a New Theory on the Measurement of Risk," Econometrica, $22,23-36$.

Chateauneuf, A., And G. Lakhnati (2007): "From Sure to Strong Diversification," Economic Theory, $32,511-522$.

Chateauneuf, A., And J.-M. TAllon (2002): "Diversification, Convex Preferences and Non-empty Core in the Choquet Expected Utility Model," Economic Theory, 19, 509-523.

Cubitt, R. (1998): "Dynamic Choice and the Common Ratio Effect," Economic Journal, 108(450), 1362-1380.

DARWin, C. (1859): On the Origin of Species by Means of Natural Selection, or the Preservation of Favoured Races in the Struggle for Life. John Murray, Albemale Street, London.

De Giorgi, E. G., And O. Mahmoud (2016): "Diversification Preferences in the Theory of Choice," Decisions in Economics and Finance, 39(2), 143-174.

(2017): "How Elementary is Diversification? A Study of Childrens' Portfolio Choice," Working Paper, University of St. Gallen.

DeAn, M., And P. ORToleva (2017): "Allais, Ellsberg, and Preferences for Hedging," Theoretical Economics, 12, 377-424.

DEKEL, E. (1989): "Asset Demands Without the Independence Axiom," Econometrica, 57, 163-169.

Eliaz, K., And G. R. Frechette (2008): “Don't Put All Your Eggs in One Basket: An Experimental Study of Falso Diversification," Working Paper, Brown University.

FERNANDES, D. (2013): “The 1/N Rule Revisited: Heterogeneity in the Naive Diversification Bias," International Journal of Marketing Research, 30(3), 310-313.

Föllmer, H., AND A. Schied (2010): "Coherent and Convex Risk Measures," in Encyclopedia of Quantitative Finance, ed. by R. Cont, pp. 355-363. John Wiley and Sons.

Gigerenzer, G. (2010): Rationality for Mortals: How People Cope with Uncertainty. Oxford University Press.

Gneezy, U., And J. Potters (1997): "An Experiment on Risk Taking and Evaluation Periods," Quarterly Journal of Economics, 112(2), 631-645.

HADAR, J., AND W. R. RUSSELl (1969): "Rules for Ordering Uncertain Prospects," American Economic Review, 59, 25-34.

(1971): "Stochastic Dominance and Diversification," Journal of Economic Theory, 3, 288305.

HALEVy, Y. (2007): “Ellsberg Revisited: An Experimental Study," Econometrica, 75(2), 503-536. 
HeY, J. D., AND J. LEE (2005): “Do Subjects Separate (or Are They Sophisticated)?,” Experimental Economics, 8, 233-265.

Hopper, K. R. (1999): "Risk Spreading and Bet Hedging in Insect Population Biology," Annual Review of Entomology, 44, 535-560.

Imas, A., S. Sadoff, And A. SAmek (2017): "Do People Anticipate Loss Aversion?," Management Science, 63(5), 1271-1284.

KAhn, B. E., AND R. K. RATnER (2005): "Variety for the Sake of Variety? Diversification Motives in Concumer Choice," in Inside Consumption: Consumer Motives, Goals, and Desires, ed. by S. Ratneshwar, and D. G. Mick, chap. 6. Taylor and Francis Group.

Kahneman, D., And A. TVersky (1984): "Choices, Values, and Frames," American Psychologist, 39(4), 341-350.

(1992): "Advances in Prospect Theory: Cumulative Representation of Uncertainty," Journal of Risk and Uncertainty, 5, 297-323.

LI, C.-K., AND W.-K. Wong (1999): "Extension of Stochastic Dominance Theory to Random Variables," RAIRO Operations Research, 33, 509-524.

LIST, J. A. (2004): "Neoclassical Theory Versus Prospect Theory: Evidence from the Marketplace," Econometrica, 72, 615-625.

Loomes, G. (1991): "Evidence of a New Violation of the Independence Axiom," Journal of Risk and Uncertainty, 4(1), 91-108.

MANN, H. B., AND D. R. Whitney (1947): "On a Test of Whether One of Two Random Variables is Stochastically Larger than the Other," Annals of Mathematical Statistics, 18(1), 50-60.

MARKowitz, H. M. (1952): "Portfolio Selection,” Journal of Finance, 7, 77-91.

Olofsson, H., J. RIPA, AND N. JonzÉN (2009): "Bet-hedging as an Evolutionary Game: the Tradeoff Between Egg Size and Number," Proceedings of the Royal Society B.

RABin, M., AND R. H. Thaler (2001): "Anomalies: Risk Aversion," Journal of Economic Perspectives, $15,219-232$.

Rajon, E., E. Desouhant, M. Chevalier, F. Debias, and F. Menu (2014): “The Evolution of Bet Hedging in Response to Local Ecological Conditions," American Naturalist, 184(1).

READ, D., And G. Loewenstein (1995): "Diversification Bias: Explaining the Discrepancy in Variety Seeking Between Combined and Separated Choices," Journal of Experimental Psychology: Applied, 1(1), 34-49.

Rizzo, J. A., And R. J. Zeckhauser (2004): "Reference Incomes, Loss Aversion, and Physician Behavior," Review of Economics and Statistics, 85, 909-922. 
Rubinstein, A. (2002): "Irrational Diversification in Multiple Decision Problems," European Economic Review, 46(8), 1369-1378.

SAmuelson, P. (1967): "General Proof that Diversification Pays," Journal of Financial and Quantitative Analysis, 2, 1-13.

SAmuelson, W., And R. J. Zeckhauser (1988): "Status Quo Bias in Decision Making," Journal of Risk and Uncertainty, 1(1), 7-59.

SCHMEIDleR, D. (1989): "Subjective Probabilty and Expected Utility without Additivity," Econometrica, 5, 571-587.

Shin, J., AND D. ARIELY (2004): "Keeping Doors Open: The Effect of Unavailability on Incentives to Keep Options Viable,” Management Science, 50(5), 561-708.

Simonson, I. (1990): "The Effect of Purchase Quantity and Timing on Variety-Seeking Behavior," Journal of Marketing Research, 27, 150-162.

StArmer, C. (1991): "Does the Random Lottery Incentive System Elicit True Preferences?," American Economic Review, 81(4), 971-978.

Starrfelt, J., AND H. KoKko (2012): "Bet Hedging - A Triple Trade-off Between Means, Variances and Correlations," Biological Reviews of the Cambridge Philosophical Society, 87(3), 742-755.

STRACCA, L. (2002): “The Optimal Allocation of Risks Under Prospect Theory," European Central Bank, Working Paper No. 161.

Tesfatsion, L. (1976): "Stochastic Dominance and Maximization of Expected Utility," Review of Economic Studies, 43, 301-315.

Thaler, R. H., A. Tversky, D. Kahneman, And A. Schwartz (1997): "The Effect of Myopia and Loss Aversion on Risk Taking: An Experimental Test," Quarterly Journal of Economics, 112(2), 647-661.

von Neumann, J., And O. Morgenstern (1944): Theory of Games and Economic Behavior. Princeton University Press.

WAKKER, P. (1990): "Characterizing Optimism and Pessimism Directly through Comonotonicity," Journal of Economic Theory, 52, 453-463. 


\section{A Experimental instructions}

Introductory instructions. You are participating in an experiment conducted by researchers at the University of St. Gallen. The experiment asks you to make a series of choices among alternatives that involve monetary prizes. It specifically consists of a sequence of choice questions that ask you to play certain dice-rolling games. Each game and each question will be explained in detail as you go on.

We are only interested in your personal preferences, so please take the time to think about what exactly you would prefer to do before you answer each question. You should expect to complete the experiment in no more than 30 minutes.

Your anonymity will be completely preserved. 10 of the total number of participants will receive a reward based on their choice in only ONE randomly selected game from Question 1. Questions 2 and 3 are rewarded. You will only see the output of each game and your potential reward once you finish the experiment.

Thank you in advance for your participation!

Question 1. You have CHF 100 to be allocated to 2 identical dice, D1 and D2, both of which have 3 sides colored in blue and 3 sides colored in red. Both dice will be rolled simultaneously. If D1 lands on red, you win the amount that you allocated to D1, otherwise you loose that amount. Similarly, if D2 lands on red, you win the amount that you allocated to D2, otherwise you loose that amount.

Note that in the majority of the following cases, there is a cost associated with splitting your CHF 100 endowment amongst the two dice, but there is no cost associated with allocating your entire endowment to one of the two dice.

Also note that only one randomly selected choice alternative from the following 13 cases will be rewarded.

How do you choose to allocate your CHF 100 to D1 and D2:

\begin{tabular}{|l|l|l|l|}
\hline & Cost of allocation & D1 & D2 \\
\hline Case 1 & $0.00 \mathrm{CHF}$ & & \\
\hline Case 2 & $0.10 \mathrm{CHF}$ & & \\
\hline Case 3 & $0.20 \mathrm{CHF}$ & & \\
\hline Case 4 & $0.50 \mathrm{CHF}$ & & \\
\hline Case 5 & $1.00 \mathrm{CHF}$ & & \\
\hline Case 6 & $2.00 \mathrm{CHF}$ & & \\
\hline Case 7 & $3.00 \mathrm{CHF}$ & & \\
\hline Case 8 & $5.00 \mathrm{CHF}$ & & \\
\hline Case 9 & $8.00 \mathrm{CHF}$ & & \\
\hline Case 10 & $10.00 \mathrm{CHF}$ & & \\
\hline Case 11 & $1 \%$ of allocation to D1 & & \\
\hline Case 12 & $\mathbf{5 \%}$ of allocation to D1 & & \\
\hline Case 13 & $10 \%$ of allocation to D1 & & \\
\hline
\end{tabular}


Question 2. You are offered CHF 10, and you can either keep it or use some or all of it to play the following game. A fair die with 3 sides in blue and 3 sides in red is rolled. If the die lands on red, you receive double the amount used to play the game, otherwise you loose that amount.

How much of your CHF 10 endowment do you choose to keep and how much do you use to play the game?

Keep (in CHF):

Play (in CHF):

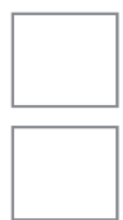

Question 3(A). For each of the 10 choices below, choose either option A or option B. If you choose option A, you will receive the corresponding amount of money specified (between CHF 0.50 and CHF 5). If you choose option B, you will receive either CHF 5 or CHF 0, depending on the outcome of rolling the fair die with 3 sides colored in red and 3 sides colored in blue.

Option A: CHF 0.5/1/1.5/2/2.5/3/3.5/4/4.5/5 for sure

Option B: If red, then CHF 5, if blue then CHF 0

Question 3(B). For each of the 10 choices below, choose either option A or option B. If you choose option A, you will receive the corresponding amount of money specified (between CHF 0.50 and CHF 5). If you choose option B, you will receive either CHF 5 or CHF 0, depending on the outcome of rolling the fair die with 3 sides colored in red and 3 sides colored in blue.

Option A: CHF 0 for sure

Option B: If red, then CHF $-1 /-2 /-3 /-4 /-5 /-6 /-7 /-8 /-9 /-10$, if blue then CHF 5

Question 3(C). For each of the 10 choices below, choose either option A or option B. If you choose option A, you will receive the corresponding amount of money specified (between CHF 0.50 and CHF 5). If you choose option B, you will receive either CHF 5 or CHF 0 , depending on the outcome of rolling the fair die with 3 sides colored in red and 3 sides colored in blue.

Option A: CHF -0.5/-1/-1.5/-2/-2.5/-3/-3.5/-4/-4.5/-5 for sure

Option B: If red, then CHF -5, if blue then CHF 0 